Synthesis, part of a Special Feature on Archetype Analysis in Sustainability Research

\title{
Design and quality criteria for archetype analysis
}

\author{
$\underline{\text { Klaus Eisenack }}^{1}, \underline{\text { Sergio Villamavor-Tomas }}^{2}$, Graham Epstein $^{3}$, Christian Kimmich $^{4}, \underline{\text { Nicholas Magliocca }}^{5}, \underline{\text { David Manuel-Navarrete }}^{6}$,
} Christoph Oberlack ${ }^{7,8}$, Matteo Roggero $^{1}{ }^{1}$ and Diana Sietz ${ }^{9,10}$

\begin{abstract}
A key challenge in addressing the global degradation of natural resources and the environment is to effectively transfer successful strategies across heterogeneous contexts. Archetype analysis is a particularly salient approach in this regard that helps researchers to understand and compare patterns of (un)sustainability in heterogeneous cases. Archetype analysis avoids traps of overgeneralization and ideography by identifying reappearing but nonuniversal patterns that hold for well-defined subsets of cases. It can be applied by researchers working in inter- or transdisciplinary settings to study sustainability issues from a broad range of theoretical and methodological standpoints. However, there is still an urgent need for quality standards to guide the design of theoretically rigorous and practically useful archetype analyses. To this end, we propose four quality criteria and corresponding research strategies to address them: (1) specify the domain of validity for each archetype, (2) ensure that archetypes can be combined to characterize single cases, (3) explicitly navigate levels of abstraction, and (4) obtain a fit between attribute configurations, theories, and empirical domains of validity. These criteria are based on a stocktaking of current methodological challenges in archetypes research, including: to demonstrate the validity of the analysis, delineate boundaries of archetypes, and select appropriate attributes to define them. We thus contribute to a better common understanding of the approach and to the improvement of the research design of future archetype analyses.
\end{abstract}

Key Words: abstraction; archetype analysis; generalization; ideographic trap; interdisciplinary collaboration; panacea; pattern; research design; social-ecological systems; qualitative; quantitative; validity

\section{INTRODUCTION}

Natural resources and the environment continue to degrade all over the globe, even though we have known about these problems for decades. There is thus an urgent need for new ways to build knowledge that both explains the drivers of sustainability problems and helps to find solutions in diverse social and ecological contexts. Many scholars and experts emphasize the need for inter- or transdisciplinary approaches and methodological pluralism to address this challenge (e.g., Poteete et al. 2010, Ruppert-Winkel et al. 2015, Karpouzoglou et al. 2016, Defila and Di Giulio 2018). Those approaches, however, frequently suffer from inconsistent quality criteria (Defila and Di Giulio 2015, Belcher et al. 2016). Shared quality criteria are crucial to support rigorous research designs that lead to high quality outcomes, better knowledge integration, and ultimately, improved decision making (Bergmann et al. 2005, StollKleemann and Pohl 2007, Belcher et al. 2016, Magliocca et al. 2018).

One rapidly developing approach to study the sustainability of social-ecological systems in inter- and transdisciplinary settings is archetype analysis (UNEP 2007, for a systematic review see Oberlack et al. 2019). Archetype analysis, as understood in sustainability research, is a comparative approach that seeks to identify recurrent patterns among cases in which general regularities that apply to all cases cannot be expected (Eisenack et al. 2006). The number of applications of archetype analysis has risen in recent years (Oberlack et al. 2019), giving rise to a growing portfolio of methods (Sietz et al., 2019). However, researchers currently face a lack of standard research designs and quality criteria. Such criteria would help to address common methodological challenges when designing and conducting archetype analyses. Archetype analysis is thus not an exception to the general difficulties and problems affecting inter- and transdisciplinary sustainability research. We therefore aim to contribute to the development of quality criteria to guide researchers applying diverse theories and methods when they design future archetype analyses.

The growing body of scholarship on archetypes demonstrates its value to the theory and practice of sustainability and consolidates unifying assumptions of the approach (Oberlack et al. 2019). Archetype analysis generally rejects a single universal model that explains or seeks to achieve sustainability across a complete universe of cases (Young et al. 2006). This addresses concerns that sustainability research is frequently complicated by the diversity of social, ecological, and institutional contexts (Warren 2002, Schachhuber 2004, Ostrom 2005, Padmanabhan and Jungcurth 2012). Neglecting this diversity can lead to the imposition of policies that are fundamentally at odds with the social-ecological conditions in which they are implemented (Brown 2003, Acheson 2006, Epstein et al. 2015). In contrast, archetype analysis identifies multiple recurrent patterns (archetypes) that function as building blocks to explain outcomes in multiple, more or less heterogeneous cases (Eisenack 2012, Oberlack and Eisenack 2018). It characterizes and classifies environmental problems and opportunities, explains each class based on a theory, and thereby enables planners and policymakers to learn from the experience of others working in different areas to address similar problems (Eisenack et al. 2006, UNEP 2007, Kok et al. 2016).

\footnotetext{
${ }^{1}$ Resource Economics Group, Humboldt-Universität zu Berlin, Berlin, Germany, ${ }^{2}$ Institute of Environmental Science and Technology (ICTA), Autonomous University of Barcelona, Barcelona, Spain, ${ }^{3}$ Environmental Change and Governance Group, School of Environment, Resources and Sustainability, University of Waterloo, Canada, ${ }^{4}$ Department of Environmental Studies, Masaryk University, Brno, Czechia, ${ }^{5}$ University of Alabama, Department of Geography, Tuscaloosa, Alabama, USA, ${ }^{6}$ School of Sustainability, Arizona State University, Tempe, Arizona, USA, ${ }^{7}$ Institute of Geography, University of Bern, Bern, Switzerland, ${ }^{8}$ Centre for Development and Environment (CDE), University of Bern, Bern, Switzerland, ${ }^{9}$ Potsdam Institute for Climate Impact Research, Earth System Analysis Research Domain, Potsdam, Germany, ${ }^{10}$ Wageningen University, Soil Physics and Land Management Group, Wageningen, The Netherlands
} 
Quantitative analyses are sometimes criticized for overgeneralization and disregarding the role of context (Ragin 2000, Bennett and Elman 2006), while qualitative studies are sometimes criticized for being overly specific, neglecting patterns that exist across cases (Basurto and Ostrom 2009). Archetype analysis is situated between these two extremes. It is an approach that is able to accommodate both inductive and deductive research designs, a range of qualitative and quantitative methods (e.g., cluster analysis, grounded theory, meta-analysis of case studies, process tracing and simulation; see Sietz et al. 2019), and different epistemologies.

We present a joint reflection on the insights from a survey with experts in archetype analysis and from a collaborative effort at two international research workshops (Oberlack et al. 2017, Eisenack et al. 2018). We aim to identify a coherent set of quality criteria that are consistent with reported challenges for and definitions of archetype analysis.

\section{ARCHETYPE ANALYSIS IN SUSTAINABILITY RESEARCH}

Archetype analysis generally "investigates recurrent patterns of the phenomenon of interest at an intermediate level of abstraction to identify multiple models that explain the phenomenon under particular conditions" (Oberlack et al. 2019). Within this general understanding, we adopt a view of archetypes as building blocks (instead of case typologies, that are also considered as archetype analyses by Oberlack et al. 2019) and build on the following more detailed conceptualization.

First, archetypes are nonuniversal, i.e., the analysis identifies multiple recurrent patterns across a set of heterogeneous empirical cases. The set of these patterns is called a suite of archetypes (cf. Eisenack et al. 2006, Oberlack and Eisenack 2018). Thus, an archetype does not need to hold in all cases. However, each archetype can hold in multiple cases. The archetype approach thus avoids getting stuck in the "ideographic trap" in which all cases are considered to be unique. Second, archetypes function as building blocks that can be combined with other archetypes to explain phenomena in individual cases. Multiple archetypes can thus characterize a single case. Third, a suite of archetypes and the cases of interest are described by referring to a "common vocabulary of attributes." Each description does not require the use of all attributes. Attributes can be characteristics, variables, qualities, factors, or other properties chosen at an intermediate level of abstraction to achieve a balance between case-based validity and generalization. Fourth, the analysis classifies "components of cases" (e.g., phenomena or processes within cases) that are present in subsets of the universe of cases. Thus, a single archetype does not necessarily characterize whole cases, but certain aspects of them. Classes of components of cases are described through "configurations of attributes." Each archetype is further characterized by a theory that explains the corresponding configuration of attributes. Thus, each archetype in a suite is characterized by three elements: (1) a configuration of attributes, together with (2) a theory, and (3) the set of cases in which it holds (called the domain of validity, which is a subset of the universe of cases).

Figure 1 illustrates these concepts. A suite of city archetypes might contain the patterns of global cities, cities in federal states, cities that lead in climate protection, and so on. Each archetype's theory explains its configuration of attributes, in which the attributes are taken from the common vocabulary. The vocabulary might contain, e.g., presence of fossil-fuel industries, influence of certain kinds of lobbies, participation in international standardization processes, etc. Depending on the research questions, components might be city quarters, economics sectors, or specific political processes.

Fig. 1. Simplified illustration of an archetype analysis of cities (cases represented by boxes, components by bullet points). Each archetype is characterized by a specific configuration of attributes (icons in the circles) from a common vocabulary, supplied with a theory (circle) and a domain of validity (containing all cities to which bulleted arrows from one circle lead). The approach identifies a suite of archetypes instead of a universal model. Like building blocks, archetypes can be combined in different ways to explain the unique character of individual cases (multiple arrows pointing to single boxes).

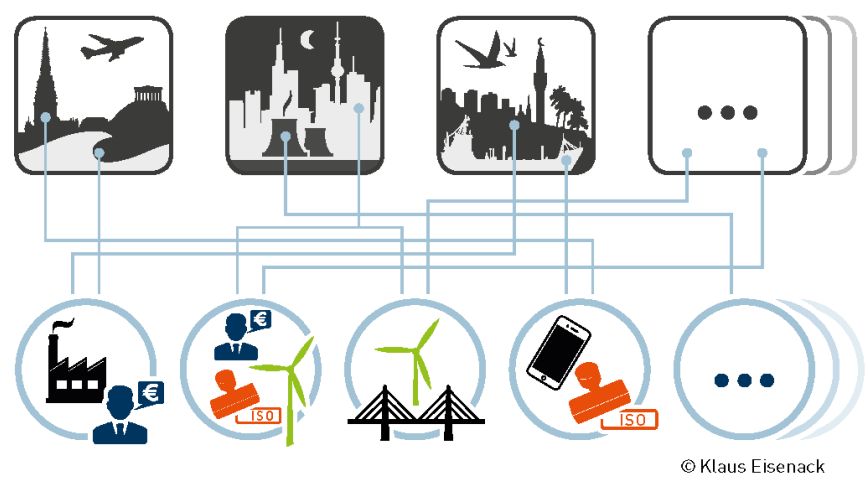

Archetypes are understood as mental representations of relationships between attributes and processes that characterize systems. The way that archetypes are developed and applied depends on the purpose of the analysis and choice of methods. The identification of archetypes can be inductive, e.g., identifying similar social-ecological patterns in a large number of locations (Sietz et al. 2017), or deductive, i.e., actively looking for manifestations of a particular theory (Manuel-Navarrete et al. 2007). Furthermore, we argue that archetype analysis is compatible with different epistemological positions (e.g., realist, constructivist, explanatory, or interpretive). Archetype analysis shares (but recombines) some features with other approaches (e.g., qualitative comparative analysis, QCA, Ragin 1989, Schneider and Wagemann 2012; multiple case studies, Yin 2009; model-centered meta-analysis, Rudel 2008; and scenario archetypes, cf. King et al. 1994, Bennett 2005, Della Porta and Keating 2008; Sitas et al. 2019). This adaptability is important to make archetype analysis suitable for inter- and transdisciplinary research.

\section{CHALLENGES FOR ARCHETYPE ANALYSIS}

One source for our argument is a survey with 28 experienced researchers, who used archetype analysis, conducted in March 2017 with a response rate of $61 \%$, covering fields including agricultural sciences, climatology, economics, environmental sciences, geography, institutional analysis, land-use science, modeling, and sociology (for more details see Oberlack et al. 2019). It yielded, inter alia, a repository of key papers and a collection of challenges. 
This collection was extended, synthesized, and discussed in a collaborative effort at two international research workshops with 46 participants based in 12 countries from Asia, Europe, and North and South America (Oberlack et al. 2017, Eisenack et al. 2018). After the first workshop, the authors developed the above definition of archetype analysis and discussed it in the second workshop. The discussion of participants' experience with tackling the collected challenges led to a set of quality criteria. For this paper, the authors prioritized challenges and quality criteria in light of the key papers and a coherent line of argument. Some remaining issues are discussed below. We now turn to the prioritized challenges.

\section{Validity of archetypes}

Archetype analysis is fundamentally motivated by the pursuit of explaining outcomes in heterogeneous cases that lack universal patterns. However, this presents a challenge: how can we establish the validity of the resulting archetype analysis? Scholars may choose to ignore contradictory evidence by invoking limits to the external validity of a given archetype (i.e., its applicability beyond the set of cases for which it has been developed). In other words, if one observation does not fit to an archetype, this does not falsify the archetype, simply because archetypes are not required to be universal. It only falsifies the applicability of that archetype in that case. In the face of this difficulty, few studies have actually taken steps to validate the archetypes they identify, and yet validation is crucial if archetype analysis is to provide theoretically and empirically rigorous and practically useful knowledge.

Internal validity refers to inferences within a particular study. If cases in the study's sample are relatively homogenous, a limited set of attributes might explain their variation; so validity could be established using standard inferential statistics. However, this approach has the potential to neglect factors that are important within particular subpopulations of cases (e.g., Keys and McConnell 2005, Sietz and Van Dijk 2015). Ultimately, internal validity of an archetype analysis depends on the validity of the (combination of) methods used to study the cases and to classify the components. This is particularly obvious for meta-analyses because they need to rely on the theories and configurations identified by the primary studies (e.g., Oberlack and Eisenack 2017, Kimmich and Villamayor-Tomás 2018).

By contrast, external validity presents a particular challenge for archetype analysis. It refers to the domains of validity, or more generally to the universe of cases in which it is expected to hold (Sietz et al. 2011, 2017, Kok et al. 2016). For example, if we find a suite of archetypes of cities from a medium-sized sample, external validity refers to our confidence in extending those to cities that are not in the sample. Standard inferential statistics approaches, for instance, aim at general results that apply to a universe of cases that is broader than the sample, or at least to all those that fall within the ranges of independent variables in the sample (King et al. 1994). In contrast, many qualitative approaches are cautious in trying to generalize beyond one or a small number of cases, placing significant limits on the transferability of research findings. Archetype analysis falls between these extremes.

\section{Boundaries of archetypes}

It is possible to conduct an archetype analysis that produces a very large suite of archetypes, each one characterized by a complex configuration of many attributes encompassing social, ecological, and technological features (processes, structures), so that each archetype only holds in a small number of cases. Alternatively, one can aim at a small suite, in which each archetype is characterized by a small and simple configuration of attributes. We might describe city archetypes by two attributes (e.g., being large/small and poor/wealthy, so that there are potentially four city classes) or by many attributes in complex relations (e.g., referring to details of topography, infrastructure, economy, culture, political system, so that there are many classes). Depending on the research question, the best balance between these extremes needs to be chosen. For instance, when should a domain of validity be divided into two archetypes with more narrow boundaries, or when should two domains be fused into one archetype with broader boundaries? The balance can be expressed by the number of attributes per archetype, but also by the number of archetypes in a suite because both perspectives tend to be closely related. For example, Oberlack and Eisenack (2018) identified a suite of 21 archetypical barriers to climate adaptation, each characterized by 2 to 4 attributes. Václavík et al. (2013) used 32 land-use indicators to obtain 12 archetypes. United Nations Environment Programmes (UNEP 2007) identified seven archetypes of vulnerability, each of which contains multiple vulnerability profiles (Kok et al. 2016). In the literature, there seems to be no systematic criterion on how to select the appropriate size, complexity, and number of archetypes.

Challenges in delineating boundaries occur frequently in pattern analysis like cluster analysis (Kaufman and Rousseeuw 1990). At one extreme we could classify all cases into one cluster, whereas at the other, we could consider each case as a cluster on its own. Although several standards have been proposed, there is still no agreement on how to determine the appropriate number of clusters, or how to interpret their meanings. Similar challenges are known in QCA (Ragin 1989), a method which seeks to determine logical conjunctions of attributes that are sufficient for an outcome. Qualitative comparative analysis produces multiple solutions, allowing the analyst to choose between more parsimonious but coarse conjunctions and more complex and precise ones.

For archetype analysis, the difficulty of defining boundaries stems more generally from a lack of clear or objective boundaries of social-ecological systems. Although ecological boundaries may be structured through species interactions (Cadenasso et al. 2003) and physical gradients (Allen et al. 2001), they are socially constructed by norms, rules, or habits (Smith and Varzi 2000). Boundaries thus depend on theoretical conceptions and the research questions of the analyst.

For the analyst, there is a trade-off between more nuanced and more coarse-grained statements. If archetypes are characterized by more attributes, their domain of validity will tend to shrink. It will be less likely that multiple archetypes hold in one case, and the theories to explain the configurations will be less parsimonious. Simply said, the challenge is to find guidelines regarding the number of attributes per archetype required to achieve an appropriate balance between generalization and highlighting meaningful differences among cases. 
Fig. 2. Recommended design and quality criteria for archetype analysis. Numbers correspond to the following subsections with more details. The four columns propose possible strategies that may be chosen in a research design to approach the quality criteria (see explanations in the text).

\begin{tabular}{|c|c|c|c|c|}
\hline $\begin{array}{l}\text { Quality } \\
\text { Criteria }\end{array}$ & $\begin{array}{c}\text { 1. Specify domains } \\
\text { of validity }\end{array}$ & $\begin{array}{l}\text { 2. Ensure ability to } \\
\text { combine }\end{array}$ & $\begin{array}{l}\text { 3. Navigate levels } \\
\text { of abstraction }\end{array}$ & $\begin{array}{l}\text { 4. Obtain fit } \\
\text { between elements }\end{array}$ \\
\hline Strategies & $\begin{array}{l}\text { - Use metrics for } \\
\text { explanatory capacity } \\
\text { or distance measures } \\
\text { - Minimum number of } \\
\text { cases per archetype } \\
\text { - Inform about } \\
\text { domains of validity } \\
\text { - Revise contradictory } \\
\text { or critical cases } \\
\text { - Diagnose new cases, } \\
\text { test against } \\
\text { additional data, split } \\
\text { sample }\end{array}$ & $\begin{array}{l}\text { - At least one case } \\
\text { with two archetypes } \\
\text { - Minimize number of } \\
\text { archetypes by } \\
\text { recombination } \\
\text { - Fuzzy clustering } \\
\text { - Classify components } \\
\text { within cases } \\
\text { - Deductive typologies }\end{array}$ & $\begin{array}{l}\text { - Avoid ideography or } \\
\text { overgeneralization } \\
\text { - Consider spatial and } \\
\text { temporal scale } \\
\text { - Consider kind and } \\
\text { level of decision } \\
\text { making } \\
\text { - Use multitiered } \\
\text { vocabulary of } \\
\text { attributes }\end{array}$ & $\begin{array}{l}\text { - Pairwise checks } \\
\text { between elements } \\
\text { - Planned iterative } \\
\text { steps, including: } \\
\text { common vocabulary, } \\
\text { data collection, } \\
\text { configurations, } \\
\text { classification, } \\
\text { domains of validity, } \\
\text { theories, abstraction, } \\
\text { naming }\end{array}$ \\
\hline
\end{tabular}

\section{Appropriate attributes}

Archetype analysis aims to achieve a balance between abstract explanations and providing contextually explicit guidance to policymakers. However, the heterogeneity of social-ecological systems and diversity of institutional arrangements often requires trade-offs between accuracy and meaning (Cox 2008). In light of this challenge, the outcome of an archetype analysis crucially depends on the common vocabulary of attributes. It is far from obvious how the attributes in the vocabulary should be determined. This involves choosing what to look at. Theories can be useful for vocabulary development but should not unnecessarily constrain empirical discovery.

One key aspect of this challenge is to achieve a selection of attributes at an appropriate level of abstraction. Starting from the premise that every case is unique in some way, archetypes can only recur in multiple cases if the attributes are sufficiently abstract. However, they should not be so abstract that important differences cannot be expressed or captured. For instance, institutional designs can be too generic to be applicable in any case because they are very abstract (panaceas, Ostrom et al. 2007). On the other hand, the very idea of transferring insights and policies between cases implies some kind of generalization. As a result, there is a clear need for guidance as to how one might systematically navigate between two extremes: meaningless overabstraction or ideographic concreteness. The challenge is to achieve an appropriate balance between the analytical relevance (or significance) of attributes and their importance for meaningful case-level descriptions.

Archetype analysis also requires preanalytical decisions about which levels and scales of attributes and cases of interest will be relevant for the analysis (Kay 2008, Giampietro et al. 2009). Some decisions refer to the geographic scales and places in which the archetypes are expected to hold, e.g., from global to local (Sietz et al. 2011, Vidal Merino et al. 2018), at multiple scales (e.g., Sietz 2014, Sietz et al. 2017), or combining individual and organizational levels (Villamayor-Tomás and García-López 2017). Other decisions refer to the level of detail at which variables are measured, and the dimensions that are emphasized, which may include biophysical, socio-political, politico-economic, cultural, or psychological factors (e.g., Hofstede 1983, Cash et al. 2006, Anderies et al. 2013, Davidson 2013, Hatt 2013, Kimmich 2013, Sietz 2014, Manuel-Navarrete 2015, Manuel-Navarrete and Pelling 2015, Schmid et al. 2017). Further decisions relate to the resolution of institutional arrangements or options for decision making considered (Oberlack 2017). The social-ecologicalsystems framework, for instance, generally conceptualizes the universe of sustainability problems as common-pool resource problems (Frey and Cox 2015) and has been even broadened in scope (McGinnnis and Ostrom 2014). Common-pool resource problems can be further subdivided, to consider cases with rules for enforcement (Ostrom 1990, Cox et al. 2010) or, more specifically, third-party enforcement (Agrawal and Goyal 2001). Recurrent archetypes in resource governance, such as dilemmas or coordination problems, can be building blocks that are nested within recurrent network configurations of those situations (Kimmich and Villamayor-Tomás 2018).

Finding the appropriate set of attributes represents thus a major challenge for archetype analysis. It is however paramount to avoiding both overgeneralization and the ideographic trap. There is a clear need for strategies and guidance to determine the level of abstraction and the size of the common vocabulary of attributes.

\section{QUALITY CRITERIA}

Based on the above, we suggest four quality criteria to further advance archetype analysis (see Fig. 2). In addition, we provide suggestions for research strategies to achieve these quality criteria. Naturally, the criteria are additional to general standards for good scientific practice, and the specific standards of particular methods used in the analysis.

Figure 2 denotes the Recommended design and quality criteria for archetype analysis. Numbers correspond to the following subsections with more details. The four columns propose possible strategies that may be chosen in a research design to approach the quality criteria (see explanations in the text). 
An archetype analysis should specify the domain of validity for each archetype (1)

Establishing validity enhances the credibility of any archetype analysis. This can build, in part, on the standards of the particular methods chosen for an archetype analysis. It is helpful to distinguish between the validity of a single archetype and the validity of a suite of archetypes, as well as between internal and external validity.

To assess the internal validity of single archetypes, it is good practice to examine their explanatory capacity in accordance with the chosen methods. In QCA, for example, consistency scores provide information about the proportion of cases in which a configuration is associated with a given outcome. A common recommendation is to revise "contradictory" cases that diverge from expected outcomes. This usually results in the addition of attributes or configurations (Ragin 2008). Additionally, it is essential to explain why and how the attributes are interrelated as a configuration. Internal validity can be provided through casebased qualitative methods (e.g., Neudert et al. 2019), for instance by process tracing (Rihoux 2006, Elo and Kyngäs 2008, Collier 2011). In cluster analyses, domains of validity can be established based on numerical grid-cell data (Václavík et al. 2013, 2016, Levers et al. 2018).

To assess the internal validity of a whole suite, the validity of the classification of the components of cases needs to be demonstrated in conformity with methodological standards, e.g., distance measures to assess whether a case belongs to a cluster (Kaufman and Rousseeuw 1990), or the closure criterion in formal concept analysis (Ganter et al. 2005; Wang et al. 2019), or deductively, or by standards of qualitative methods. In metastudies, the common vocabulary of attributes should be subject to intercoder reliability checks, and the obtained archetypes can be revalidated using primary studies (Oberlack and Eisenack 2018, Kimmich and Villamayor-Tomás 2018). In frequency-based meta-analyses, justified thresholds for the minimum number of cases in which an archetype should hold are recommended to be proportional to the size of the case sample (e.g., two cases in Oberlack and Eisenack 2018; A. Gotgelf, M. Roggero, and K. Eisenack, unpublished manuscript). Typically, a higher threshold will identify fewer and less detailed archetypes in any given population.

To determine the external validity of a single archetype, precise information about its domain of validity is important (Magliocca et al. 2018), for example through an analysis of critical cases (Yin 2009), or field experiments (U. Kasymov, X. Wang, D. Zikos, et al., unpublished manuscript). If data allow, statistical models and correlation analyses can test the validity of archetypes against different scope conditions (Brambor et al. 2006, Ragin 2008).

External validity of a whole suite can be assessed by studying new cases and checking whether they are already covered by the suite of archetypes. It can also be assessed by adding more attributes to see if this does not require an extension of the suite. For example, vulnerability archetypes among farming households identified through cluster analysis were validated by Sietz et al. (2012) by comparing them to separate vulnerability outcome data. In some situations, researchers might be able to split the sample using one subsample to perform the analysis and the other to test the resulting suite of archetypes.
An archetype analysis should ensure that multiple archetypes can be combined in different ways to characterize single cases (2) Archetype analysis analytically decomposes cases into components that are classified by identifying recurrent configurations of attributes. Then, multiple archetypes can be combined, like building blocks, to produce a comprehensive picture of a single case (Eisenack 2012). Building blocks allow us to economize upon the number of archetypes needed to characterize heterogeneous cases. The challenge is to determine the appropriate boundaries of the building blocks, which in turn will delimit the archetypes' domains of validity.

Think of the following hypothetical example. Assume an archetype analysis of 100 cases and an even larger set of attributes. Suppose there is considerable case heterogeneity so that the cases can be grouped into 30 classes, each with 3 or 4 cases that share all attributes. If each class was considered as an archetype, this would be tractable, but with difficulty; it would clearly be an advantage if we could capture the same heterogeneity with fewer archetypes. This is possible, in principle, if we do not require all cases within an archetype's domain of validity to share all attributes. When classifying cases based on partial attribute agreement, a smaller number of classes (albeit overlapping) is obtained. If we consider these partially shared configurations of attributes as archetypes, just 5 of them might be sufficient to cover all 100 cases. Those 5 archetypes can combine like building blocks in 31 different ways, so that almost every combination may represent one of the original case classes. This economizing aspect of the building-blocks principle becomes increasingly important for larger sets of cases. Based on experience, it is probably good practice to aim for 4 to 30 archetypes in an analysis, with at least 1 case in which more than 1 archetype holds. If there are very many archetypes, or if they never combine, they are probably too specific and there may be potential for greater generalization. If there are fewer than four archetypes, data might be sufficiently homogeneous to employ conventional analytical approaches.

In operational terms, there are different ways to identify the appropriate number of archetypes for a particular study (see also Sietz et al. 2019). A quantitative approach is to identify recurrent configurations of attributes in the data by cluster analysis (e.g., Sietz et al. 2011, 2017, Kok et al. 2016) or self-organizing maps (Václavík et al. 2013, Levers et al. 2018). The number of clusters, each representing a class of cases, can be chosen using stabilitybased procedures (Sietz et al. 2011, Janssen et al. 2012). Although crisp classification categorizes each case by exactly one archetype, other techniques like fuzzy clustering reveal the degree of membership of a case in one or several clusters without sharp boundaries (Ramachandra and Srinivas 2006, Cullum et al. 2017), so that clusters can be understood as building blocks.

Further suitable qualitative or quantitative methods to classify recurrent components within cases include grounded theory (Corbin and Strauss 2008, Moser et al. 2019), QCA (e.g., Srinivasan et al. 2012, Crona et al. 2015, Roggero 2015), formal concept analysis (e.g., Oberlack and Eisenack 2017; Wang et al. 2019), sensitivity analysis (e.g., Messerli et al. 2015), interpretive analysis of model-centered meta-analysis (e.g., Oberlack 2017), participatory systems mapping (e.g., Kopainsky et al. 2017), or analytical narratives (Bates et al. 1998, Kimmich 2016). Sometimes, multiple methods can be productively combined (e. 
g., S. Villamayor-Tomás, I. Iniesta-Arandia, and M. Roggero, unpublished manuscript). Archetypes then classify similar outcomes (e.g., Crona et al. 2015), similar processes (e.g., Oberlack et al. 2016), or similar configurations of causal effects (e.g., Manuel-Navarrete et al. 2007, Messerli et al. 2015). Because multiple components can occur in single cases, multiple archetypes can be combined.

Depending on the research question, different deductive typologies for configurations of attributes can be used (e.g., Fischer et al. 2017). If the analysis employs multiple typologies, each provides separate archetypes that can combine in different combinations to characterize single cases. For cities, one might consider the archetype of global cities (Sassen 1991), cities as growth machines (Logan and Molotch 1987), and shrinking cities (e.g., Couch et al. 2005). There are cities in the domain of validity of two of those archetypes. It might be possible that some theories provide more than one archetype, e.g., cultural theory (Douglas and Wildavsky 1983, Thompson et al. 1990, Ripberger et al. 2014; S. Pedde, K. Kok, K. Hölscher, et al., unpublished manuscript). Grid/group theory may explain how certain cities approach risks related to air pollution in different ways. These archetypes can then be combined with other typologies in one suite.

An archetype analysis should explicitly navigate through different levels of abstraction (3)

Choosing the appropriate attributes involves analytical decisions about the level of abstraction on which cases and attributes are selected. In an archetype analysis of cities, for instance, we might navigate between cases being households, quarters, administrative boundaries, or metropolitan areas. We might navigate from more abstract attributes like proneness to corruption in general, over vested interests in certain sectors, down to the influence of specific organizations. We might navigate from average annual precipitation down to seasonal or monthly precipitation. Although this tension is implicit in many scientific approaches, archetype analysis requires to purposefully deal with the entailed trade-offs to obtain nonuniversal but recurrent patterns. As far as possible, the resolution at which attributes are described should be commensurate with the variation that is actually observable. If the attributes of interest are few and coarsely described, data may be more accessible, but with more risk of overgeneralization. Conversely, specifying (many) attributes at fine resolution may produce more precise analyses capable of identifying specific causal mechanisms in a few cases, but makes it difficult to compare cases.

Because the appropriate level of abstraction typically will not be clear at the outset, it can be helpful to purposefully shift between more concrete and more abstract levels to decide on an appropriate level. This can be done using diagnostic approaches such as Ostrom's social-ecological-systems framework (Ostrom 1990, 2009, Ostrom et al. 2007, Epstein et al. 2015). This framework aims to provide scholars with a common vocabulary of attributes for describing, understanding, and predicting environmental and social outcomes in diverse social and ecological contexts. Attributes are organized hierarchically; whereby more concrete tiers provide greater specificity and refinement to attributes on more abstract tiers. An attribute at a more abstract tier can be considered to hold if at least one of the refinements of this attribute holds. A similar approach to multitiered coding systems is common in grounded theory (Corbin and Strauss 2008). For example, the archetype analysis by Oberlack and Eisenack (2017) considered six attributes in the most abstract tier, each refined by about five attributes in the next tier, e.g., social connectivity, which is further refined by two attributes in an even more concrete tier, limited vertical and limited horizontal coordination. Oberlack and Eisenack (2014) used a three-tier system in a similar way. For navigating levels of abstraction, QCA or formal concept analysis could be applied to attributes at different levels of abstraction, and the quality of the solution formulas can be compared among them. Similarly, cluster analysis or grounded theory could be used to navigate variables at different levels of abstraction. Typically, an archetype analysis with more abstract attributes will produce a smaller suite.

From our experience, we suggest organizing attributes in two to four levels of abstraction (tiers). At least two levels are needed to test different abstraction levels, but too many levels might prove intractable and difficult to communicate and explain (see Achen 2002). The number of attributes on each level needs to be tractable and will depend on the research question. There might be three to six attributes on the most abstract level. With only two attributes, conventional approaches might be more appropriate. If there are too many attributes on the most abstract level, the analysis is more likely to run into an ideographic trap. On the most concrete level, however, it might not be a problem if the number of attributes is larger than the number of cases because of the hierarchical organization. During the archetype analysis, a fit between configurations of attributes, empirical evidence, and theories can be sought for at each level to find out which level balances generalization and ideographic concreteness to provide the most useful number of insightful archetypes with respect to the research question, available data, and the kind of institutional arrangements or level of decision making that the analysis aims to inform. It is important however to avoid mixing attributes with different levels of abstraction in one archetype.

\section{Each archetype in a suite should obtain a fit between its} configuration of attributes, theory, and empirical evidence (4) An archetype analysis that is designed to satisfy the above criteria in a coherent way has the greatest prospects of generating new, theoretically rigorous, and practically useful knowledge. This fourth quality criterion brings them all together. First, an archetype analysis requires that the three elements characterizing each archetype (configuration of attributes, corresponding theory, domain of validity) are made explicit. Second, care is needed to ensure that the three elements are coherent with each other. If, for example, recurrent configurations are determined but the theories do not explain them, this indicates an absence of fit. This criterion can be viewed from two perspectives. The first is how to check whether a concluded analysis has achieved it, and the second is how to obtain it.

A number of procedures can be applied to check for a requisite fit between the three elements. One can pick any pair out of those three and check whether it is made explicit and whether it is coherent. If the three possible pairs are successfully checked for all archetypes, a fit is obtained. For example, in a primarily deductive study, Cox et al. (2010) used selected cases to study the validity of Ostrom's (1990) design principles for governing local commons. If considered as an archetype analysis, the cases of 
community-based natural resource management comprise the domains of validity. However, the configurations of attributes that explain each principle are not explicitly stated, so it is difficult to assess their fit to the underlying theories. Eisenack (2012) characterized archetypes of adaptation based on anecdotal evidence and theory-driven arguments (e.g., principal agent relations). Because attributes and domains of validity are unclear, a fit between those cannot be checked. Further examples use cluster analysis to obtain a precisely determined fit between configurations and domains of validity in studies of land-use change (Václavík et al. 2013, 2016, Levers et al. 2018). However, they have not formulated a robust theoretical explanation of the corresponding archetypes. By contrast, metastudies by Oberlack et al. (2016) and Oberlack and Eisenack (2017) started from casebased validity in the primary studies. Recurrent configurations of attributes are identified, domains of validity in the case sample are reproducibly characterized by the configurations, and theoretical entry points to explain groups of similar configurations are given. The SESMAD project (Cox 2014) studied large-scale social-ecological systems using a coherent vocabulary of attributes that allows expression of domains of validity, configurations, and theories. It can then be checked whether the theories explain the configurations, whether the configurations correctly map the domains, and whether the cases in the domains support the respective theory.

A fit can be obtained if analysis follows iterative steps that specifically concentrate on configurations, theories, or domains of validity, possibly with a mix of qualitative and quantitative methods. Although this can present an immense analytical challenge and has not been achieved by most archetype analyses thus far, we believe that it is indispensable to advance the approach. The sequence of iterative steps should be planned ahead and will depend on the aims of the research, for example whether it is oriented toward inductively building or deductively testing theories, whether it is more positive or more action oriented, and so on. Nonetheless, we argue that the following steps need to appear somewhere in the sequence: constructing the common vocabulary; collecting data and studying cases; classifying components of cases; identifying recurrent configurations and characterizing their domains of validity; developing theories to explain configurations; finding the appropriate level of abstraction; and developing a useful naming convention for each obtained archetype.

\section{DISCUSSION}

The proposed quality criteria address gaps acknowledged in previous archetype analyses and, at the same time, provide more precision to the specific character of the approach. On the other hand, we need to acknowledge that not every archetype publication will be able to meet the highest standards given the usual constraints to research. Moreover, the survey and the workshops identified further challenges that need to be addressed (see also Oberlack et al. 2019). These include the following:

1. Although archetype analysis is designed to provide a methodological grounding for interdisciplinary research, challenges remain in integrating methods from different epistemic communities. We therefore need to develop best practices on how to let qualitative and quantitative methods resonate in a single archetype analysis in the most productive way. This is even more challenging for transdisciplinary research designs.

2. The above quality criteria do not address how archetype analysis can become policy relevant. For action-oriented analyses, application validity (Bossel 1994) is essential. A specific promise of archetype analysis is the ability to transfer best practices between cases with shared archetypes. Although some attempts have been made in this respect (UNEP 2007), proven strategies to achieve this (including assessments by field experts or decision makers) are still pending.

3. Although validity is important for any method, establishing causality with archetype analysis is a further issue (see also Oberlack et al. 2019). This is not straightforward if scholars with different epistemic positions on causality collaborate. Establishing causality also depends on the kind of data available and on the specific methods applied under the umbrella of an archetype analysis (see Sietz et al. 2019).

4. Cases are typically defined as units of analysis for archetypes analysis. However, in sustainability studies, cases are frequently interdependent, linked, or telecoupled to other cases through biophysical interdependence, externalities, markets, or by being part of multi-layered or polycentric governance systems. Vocabularies currently in use may need to be expanded in order to specify attributes of spatial relations and functional linkages.

Finally, archetype analysis is currently mostly static in character, neglecting patterns of change over time or, at best, considering dynamics in a simplified way (Reckien et al. 2011, Lüdeke et al. 2014, Levers et al. 2018). However, many problems of and pathways to sustainable development emerge and evolve over time (e.g., Eisenack 2016). Although existing theories of change might help in a particular dynamic archetype analysis (e.g., panarchy, Gunderson and Holling 2002; path dependence, David 1985, Arthur 1989; systems archetypes, Wolstenholme 2003), it would additionally require a common vocabulary of change to represent different time scales or to link static archetype analyses over time. Quality criteria and guidelines for such analyses are still needed.

Despite these current limitations, existing research on archetypes has already laid an important foundation for a better understanding of environmental degradation and vulnerability, as well as options for a more sustainable future. The approach contributes to an emerging recognition of the need to contextualize global change processes while simultaneously generalizing local change within broader trends.

\section{CONCLUSIONS}

This paper is part of wider efforts toward the definition of shared principles for research quality in inter- and transdisciplinary sustainability studies (e.g., Defila and Di Giulio 2015, Magliocca et al. 2018). Specifically, it contributes to a common understanding of archetype analysis, its scope and current challenges, and to the improvement of research designs. Drawing on experience from different research fields and epistemic communities, it is to our knowledge the first attempt to formulate generally applicable quality criteria for archetype analysis. By identifying strategies to achieve them, our aim is to help scholars judge whether archetype analysis is appropriate for their research questions and provide guidance for planning their research. 
Based on a survey and two workshops with scholars experienced in archetype analysis, we identified several challenges in which the following were prioritized: (1) how to establish the validity of a suite of archetypes; (2) how to delineate the boundary of archetypes; and (3) how to find the appropriate attributes. We argue that these challenges can be addressed through the adoption of four quality criteria: (1) each archetype in a suite of archetypes should precisely specify and justify its domain of validity; (2) archetypes should be constructed so that they can be consistently combined in different ways to characterize single cases; (3) the common vocabulary of attributes should be multitiered to explicitly navigate different levels of abstraction; and (4) a fit should be obtained between attribute configurations, domains of validity, and theories. We propose several strategies for achieving these quality criteria to guide the design of future archetype analyses.

Because archetype analysis is a recent innovation, future research will undoubtedly provide input for further development and improvement of the quality criteria we have outlined. We hope our recommendations serve as a starting point for such an endeavor. We believe that adoption of the proposed criteria will further increase the potential of archetype analysis to contribute toward the development of the integrated and yet nuanced perspectives that are urgently needed to address sustainability problems in a heterogeneous world.

Responses to this article can be read online at: http://www.ecologyandsociety.org/issues/responses. php/10855

\section{Acknowledgments:}

This work has received financial support from the Swiss National Science Foundation (grant no. IZ32Z0_173396), the Institute of Geography, University of Bern (research cluster "Governing telecoupled resource systems for environmental justice"), the Nachwuchsförderpool, University of Bern, and HumboldtUniversität zu Berlin (Resource Economics Group). The paper contributes to the Global Land Programme.

\section{LITERATURE CITED}

Achen, C. H. 2002. Toward a new political methodology: microfoundations and art. Annual Review of Political Science 5 (1):423-450. https://doi.org/10.1146/annurev.polisci.5.112801.080943

Acheson, J. M. 2006. Institutional failure in resource management. Annual Review of Anthropology 35:117-134. https:// doi.org/10.1146/annurev.anthro.35.081705.123238

Agrawal, A., and S. Goyal. 2001. Group size and collective action: third-party monitoring in common-pool resources. Comparative Political Studies 34:63-93. https://doi.org/10.1177/0010414001034001003

Allen, T. F. H., J. A. Tainter, J. C. Pires, and T. W. Hoekstra. 2001. Dragnet ecology-"Just the facts, ma'am": the privilege of science in a postmodern world. BioScience 51(6):475-485.

Anderies, J. M., C. Folke, B. Walker, and E. Ostrom. 2013. Aligning key concepts for global change policy: robustness, resilience, and sustainability. Ecology and Society 18(2):8. https:// doi.org/10.5751/ES-05178-180208

Arthur, W. B. 1989. Competing technologies increasing returns and lock-in by historical events. Economic Journal 99:116-131. https://doi.org/10.2307/2234208

Basurto, X., and E. Ostrom. 2009. Beyond the tragedy of the commons. Economia delle fonti di energia e dell'ambiente 52 (1):35-60. [online] URL: https://papers.ssrn.com/sol3/papers. cfm?abstract_id $=1304688$

Bates, R. H., A. Greif, M. Levi, J.-L. Rosenthal, and B. Weingast. 1998. Analytic narratives. Princeton University Press, Princeton, New Jersey, USA.

Belcher, B. M., K. E. Rasmussen, M. R. Kemshaw, and D. A. Zornes. 2016. Defining and assessing research quality in a transdisciplinary context. Research Evaluation 25(1):1-17. https:// doi.org/10.1093/reseval/rvv025

Bennett, A. 2005. Case studies and policy relevant theory. Pages 263-284 in A. L. George, and A. Bennett, editors. Case studies and theory development. MIT Press, Cambridge, New Jersey, USA.

Bennett, A., and C. Elman. 2006. Qualitative research: recent developments in case study methods. Annual Review of Political Science 9:455-476. https://doi.org/10.1146/annurev. polisci.8.082103.104918

Bergmann, M., B. Brohmann, E. Hoffmann, M. C. Loibl, R. Rehaag, E. Schramm, and J. P. Voß. 2005. Quality criteria of transdisciplinary research: a guide for the formative evaluation of research projects. Institute for Social-Ecological Research, Frankfurt, Germany. [online] URL: https://www.katalyse.de/wpcontent/uploads/2013/08/2005 evalunet guide.pdf"

Bossel, H. 1994. Modeling and simulation. Vieweg and Teubner Verlag, Wiesbaden, Germany.

Brambor, T., W. R. Clark, and M. Golder. 2006. Understanding interaction models: improving empirical analyses. Political Analysis 14(1):63-82. https://doi.org/10.1093/pan/mpi014

Brown, K. 2003. Integrating conservation and development: a case of institutional misfit. Frontiers in Ecology and the Environment 1(9):479-487. https://doi.org/10.2307/3868115

Cadenasso, M. L., S. T. A. Pickett, K. C. Weathers, and C. G. Jones. 2003. A framework for a theory of ecological boundaries. Bioscience 53(8):750-758.

Cash, D. W., W. N. Adger, F. Berkes, P. Garden, L. Lebel, P. Olsson, L. Pritchard, and O. Young. 2006. Scale and cross-scale dynamics: governance and information in a multilevel world. Ecology and Society 11(2):8. https://doi.org/10.5751/ES-01759-110208

Collier, D. 2011. Understanding process tracing. Political Science and Politics 44(4):823-830. https://doi.org/10.1017/S1049096511001429

Corbin, J. M., and A. L. Strauss. 2008. Basics of qualitative research: techniques and procedures for developing grounded theory. Sage, Thousand Oaks, California, USA. https://doi. org/10.4135/9781452230153

Couch, C., J. Karecha, H. Nuissl, and D. Rink. 2005. Decline and sprawl: an evolving type of urban development - observed in 
Liverpool and Leipzig. European Planning Studies 13:117-136. https://doi.org/10.1080/0965431042000312433

Cox, M. 2008. Balancing accuracy and meaning in common-pool resource theory. Ecology and Society 13(2):44. https://doi. org/10.5751/ES-02683-130244

Cox, M. 2014. Understanding large social-ecological systems: introducing the SESMAD project, International Journal of the Commons 8:265-276. https://doi.org/10.18352/ijc.406

Cox, M., G. Arnold, and S. Villamayor-Tomás. 2010. A review of design principles for community-based natural resource management. Ecology and Society 15(4):38. https://doi. org/10.5751/ES-03704-150438

Crona, B. I., T. Van Holt, M. Petersson, T. M. Daw, and E. Buchary. 2015. Using social-ecological syndromes to understand impacts of international seafood trade on small-scale fisheries. Global Environmental Change 35:162-175. https://doi.org/10.1016/ j.gloenvcha.2015.07.006

Cullum, C., G. Brierley, G. L. W. Perry, and E. T. F. Witkowski. 2017. Landscape archetypes for ecological classification and mapping: the virtue of vagueness. Progress in Physical Geography: Earth and Environment 41:95-123. https://doi.org/10.1177/03091$\underline{33316671103}$

David, P. A. 1985. Clio and the economics of QWERTY. American Economic Review 75(2):332-337.

Davidson, D. J. 2013. We still have a long way to go, and a short time to get there: a response to Fikret Berkes and Helen Ross. Society and Natural Resources 26:21-24. https://doi. org/10.1080/08941920.2012.749758

Defila, R., and A. Di Giulio. 2015. Integrating knowledge: challenges raised by the "Inventory of Synthesis". Futures 65:123-135. https://doi.org/10.1016/j.futures.2014.10.013

Defila, R., and A. Di Giulio. 2018. Partizipative Wissenserzeugung und Wissenschaftlichkeit - ein methodologischer Beitrag. Pages 39-67 in R. Defila, R. and A. Di Giulio, editors. Transdisziplinär und transformativ forschen. Springer, Wiesbaden, Germany. https://doi.org/10.1007/978-3-658-21530-9 2

Della Porta, D., and M. Keating. 2008. Approaches and methodologies in the social sciences: a pluralist perspective. Cambridge University Press, Cambridge, UK. https://doi. org/10.1017/CBO9780511801938

Douglas, M., and A. Wildavsky. 1983. Risk and culture: an essay on the selection of technological and environmental dangers. University of California Press, Berkeley, California, USA.

Eisenack, K. 2012. Archetypes of adaptation to climate change. Pages 107-122 in M. Glaser, G. Krause, B. M. W. Ratter, and M. Welp, editors. Human/nature interactions in the Anthropocene: potentials of social-ecological systems analysis. Routledge, New York, New York, USA.

Eisenack, K. 2016. Institutional adaptation to cooling water scarcity in the electricity sector under global warming. Ecological Economics 124:153-163. https://doi.org/10.1016/j.ecolecon.2016.01.016

Eisenack, K., A. Gotgelf, U. Kasymov, P. Lutz, P. Perez, C. Oberlack, and D. Sietz. 2018. Second research workshop on archetype analysis in sustainability research. Workshop report, 28th Feb.-2nd March, 2018. Humboldt University, Berlin, Germany. [online] URL: https://boris.unibe.ch/121975/1/ Oberlack_2018_Workshop\%202.pdf

Eisenack, K., M. Lüdeke, and J. Kropp. 2006. Construction of archetypes as a formal method to analyze social-ecological systems. In IDGEC Synthesis Conference of the Institutional Dimensions of Global Environmental Change. Bali, Indonesia, Dec 6-9, 2006. International Human Dimensions Programme of Global Environmental Change, Bonn, Germany. [online] URL: https://uol.de/fileadmin/user_upload/wire/fachgebiete/envdev/download/ arch-eisenack3.pdf

Elo, S., and H. Kyngäs. 2008. The qualitative content analysis process. Journal of Advanced Nursing 62(1):107-115. https://doi. org/10.1111/j.1365-2648.2007.04569.x

Epstein, G., J. Pittman, S. M. Alexander, S. Berdej, T. Dyck, U. Kreitmair, K. J. Rathwell, S. Villamayor-Thomas, J. Vogt, and D. Armitage. 2015. Institutional fit and the sustainability of socialecological systems. Current Opinion in Environmental Sustainability 14:34-40. https://doi.org/10.1016/j.cosust.2015.03.005

Fischer, J., D. J. Abson, A. Bergsten, N. F. Collier, I. Dorresteijn, J. Hanspach, K. Hylander, J. Schultner, and F. Senbeta. 2017. Reframing the food-biodiversity challenge. Trends in Ecology and Evolution 32(5):335-345. https://doi.org/10.1016/j.tree.2017.02.009

Frey, U. J., and M. Cox. 2015. Building a diagnostic ontology of social-ecological systems. International Journal of the Commons 9(2):595-618. https://doi.org/10.18352/ijc. 505

Ganter, B., G. Stumme, and R. Wille. 2005. Formal concept analysis: foundations and applications. Springer, New York, New York, USA.

Giampietro, M., K. Mayumi, and J. Ramos-Martin. 2009. Multiscale integrated analysis of societal and ecosystem metabolism (MuSIASEM): theoretical concepts and basic rationale. Energy 34(3):313-322. https://doi.org/10.1016/j.energy.2008.07.020

Gunderson, L. H., and C. S. Holling. 2002. Panarchy: understanding transformations in human and natural systems. Island, Washington, D.C., USA.

Hatt, K. 2013. Social attractors: a proposal to enhance "resilience thinking" about the social. Society and Natural Resources 26 (1):30-43. https://doi.org/10.1080/08941920.2012.695859

Hofstede, G. 1983. National cultures in four dimensions: a research-based theory of cultural differences among nations. International Studies of Management and Organization 13 (1-2):46-74. https://doi.org/10.1080/00208825.1983.11656358

Janssen, P., C. Walther, and M. K. B. Lüdeke. 2012. Cluster analysis to understand socio-ecological systems: a guideline. PIK Report 126. Institute for Climate Impact Research, Potsdam, Germany. [online] URL: https://www.pik-potsdam.de/research/ publications/pikreports/summary-report-no.-126

Karpouzoglou, T., A. Dewulf, and J. Clark. 2016. Advancing adaptive governance of social-ecological systems through theoretical multiplicity. Environmental Science and Policy 57:1-9. https://doi.org/10.1016/j.envsci.2015.11.011 
Kaufman, L., and P. J. Rousseeuw. 1990. Finding groups in data: an introduction to cluster analysis. Wiley, New York, New York, USA.

Kay, J. J. 2008. An introduction to systems thinking and framing the situation: creating a systems description. Pages 3-34 in D. Waltner-Toews, J. J. Kay, and N.-M. E. Lister. The ecosystem approach: complexity, uncertainty, andmanaging for sustainability. Columbia University Press, New York, New York, USA.

Keys, E., and W. J. McConnell. 2005. Global change and the intensification of agriculture in the tropics. Global Environmental Change 15:320-337. https://doi.org/10.1016/j.gloenvcha.2005.04.004

Kimmich, C. 2013. Linking action situations: coordination, conflicts, and evolution in electricity provision for irrigation in Andhra Pradesh, India. Ecological Economics 90:150-158. https:// doi.org/10.1016/j.ecolecon.2013.03.017

Kimmich, C. 2016. Can analytic narrative inform policy change? The political economy of the Indian electricity-irrigation nexus. Journal of Development Studies 52(2):269-285. https://doi. org/10.1080/00220388.2015.1093119

Kimmich, C., and S. Villamayor-Tomás. 2018. Assessing action situation networks: a configurational perspective on water and energy governance in irrigation systems. Water Economics and Policy 5(1):1850005. http://dx.doi.org/10.1142/S2382624X18500054

King, G., R. O. Keohane, and S. Verba. 1994. Designing social inquiry: scientific inference in qualitative research. Princeton University Press, Princeton, New Jersey, USA. https://doi. org/10.1515/9781400821211

Kok, M., M. Lüdeke, P. Lucas, T. Sterzel, C. Walther, P. Janssen, D. Sietz, and I. de Soysa. 2016. A new method for analysing socioecological patterns of vulnerability. Regional Environmental Change 16(1):229-243. https://doi.org/10.1007/s10113-014-0746-1

Kopainsky, B., G. Hager, H. Herrera, P. H. Nyanga. 2017. Transforming food systems at local levels: Using participatory system dynamics in an interactive manner to refine small-scale farmers' mental models. Ecological Modelling 362:101-110. https://doi.org/10.1016/j.ecolmodel.2017.08.010

Levers, C., D. Müller, K. Erb, H. Haberl, M. R. Jepsen, M. J. Metzger, P. Meyfroidt, T. Plieninger, C. Plutzar, J. Stürck, P. H. Verburg, P. J. Verkerk, and T. Kuemmerle. 2018. Archetypical patterns and trajectories of land systems in Europe. Regional Environmental Change 18:715-732. https://doi.org/10.1007/ $\underline{\text { s10113-015-0907-X }}$

Logan, J. R., and H. L. Molotch. 1987. Urban fortunes: the political economy of place. University of California Press, Berkeley, California, USA.

Lüdeke, M. K. B., C. Walther, T. Sterzel, M. T. J. Kok, P. Lucas, P. Janssen, and H. Hilderink. 2014. Understanding change in patterns of vulnerability. PIK Report 127. Institute for Climate Impact Research, Potsdam, Germany.

Magliocca, N. R., E. C. Ellis, G. R. H. Allington, A. de Bremond, J. Dell'Angelo, O. Mertz, P. Messerli, P. Meyfroidt, R. Seppelt, and P. H. Verburg. 2018. Closing global knowledge gaps: producing generalized knowledge from case studies of socialecological systems. Global Environmental Change 50:1-14. https:// doi.org/10.1016/j.gloenvcha.2018.03.003
Manuel-Navarrete, D. 2015. Double coupling: modeling subjectivity and asymmetric organization in social-ecological systems. Ecology and Society 20(3):26. https://doi.org/10.5751/ ES-07720-200326

Manuel-Navarrete, D., J. J. Gómez, and G. Gallopín. 2007. Syndromes of sustainability of development for assessing the vulnerability of coupled human-environmental systems. The case of hydrometeorological disasters in Central America and the Caribbean. Global Environmental Change 17(2):207-217. https:// doi.org/10.1016/j.gloenvcha.2006.07.002

Manuel-Navarrete, D., and M. Pelling. 2015. Subjectivity and the politics of transformation in response to development and environmental change. Global Environmental Change 35:558-569. https://doi.org/10.1016/j.gloenvcha.2015.08.012

McGinnis, M. D., and E. Ostrom. 2014. Social-ecological system framework: initial changes and continuing challenges. Ecology and Society 19(2):30. https://doi.org/10.5751/ES-06387-190230

Messerli, P., A. Peeters, O. Schoenweger, V. Nanhthavong, and A. Heinimann. 2015. Marginal land or marginal people? Analysing patterns and processes of large-scale land acquisitions in SouthEast Asia. Pages 136-171 in P. Messerli, C. Gironde, and C. Golay, editors. Large-scale land acquisitions: focus on South-East Asia. Brill, Boston, Massachusetts, USA. https://doi.org/10.1163/9789004304758007

Moser, S., J. Ekstrom, J. Kim, and S. Heintsch. 2019. Adaptation finance archetypes: local governments' persistent challenges of funding adaptation to climate change and ways to overcome them. Ecology and Society 24(2):28. https://doi.org/10.5751/ES-10980-240228

Neudert, R., A. Salzer, N. Allahverdiyeva, J. Etzold, V. Beckmann. 2019. Archetypes of common village pasture problems in the South Caucasus - Insights from comparative case studies in Georgia and Azerbaijan. Ecology and Society 24(3):5. https://doi.org/10.5751/ES-10921-240305

Oberlack, C. 2017. Diagnosing institutional barriers and opportunities for adaptation to climate change. Mitigation and Adaptation Strategies for Global Change 22(5):805-838. https:// doi.org/10.1007/s11027-015-9699-Z

Oberlack, C., and K. Eisenack. 2014. Alleviating barriers to urban climate change adaptation through international cooperation. Global Environmental Change 24:349-362. https://doi.org/10.1016/ j.gloenvcha.2013.08.016

Oberlack, C., and K. Eisenack. 2018. Archetypical barriers to adapting water governance in river basins to climate change. Journal of Institutional Economics 14:527-555. https://doi. org/10.1017/S1744137417000509

Oberlack, C., D. Sietz, A. de Bremond, E. Bürgi-Bonanomi, J. Dell'Angelo, K. Eisenack, E. Ellis, G. Epstein, M. Giger, A. Heinimann, C. Kimmich, M. T. J. Kok, D. Manuel-Navarrete, P. Meyfroidt, P. Messerli, T. Václavík, and S. Villamayor-Tomás. 2019. Archetype analysis in sustainability research: meanings, motivations, and evidence-based policy-making. Ecology and Society 24(2):26. https://doi.org/10.5751/ES-10747-240226

Oberlack, C., L. Tejada, P. Messerli, S. Rist, and M. Giger. 2016. Sustainable livelihoods in the global land rush? Archetypes of 
livelihood vulnerability and sustainability potentials. Global Environmental Change 41:153-171. https://doi.org/10.1016/j. gloenvcha.2016.10.001

Oberlack, C., A. Winiger, P. Kupferschmied, D. Sietz, and K. Eisenack. 2017. Research workshop archetype analysis in sustainability research: workshop report. University of Bern, Bern, Switzerland. [online] URL: https://boris.unibe.ch/121976/1/ Oberlack 2017 Workshop-report.pdf

Ostrom, E. 1990. Governing the commons. Cambridge University Press, Cambridge, UK.

Ostrom, E. 2005. Understanding institutional diversity. Princeton University Press, Princeton, New Jersey, USA. https://doi. org/10.2307/j.ctt7s7wm

Ostrom, E. 2009. A general framework for analyzing sustainability of Social-Ecological Systems. Science 325 (5939):419-422. https://doi.org/10.1126/science.1172133

Ostrom, E., M. A. Janssen, and J. M. Anderies. 2007. Going beyond panaceas. Proceedings of the National Academy of Sciences 104:15176-15178. https://doi.org/10.1073/pnas.0701886104

Padmanabhan, M., and S. Jungcurt. 2012. Biocomplexityconceptual challenges for institutional analysis in biodiversity governance. Ecological Economics 81:70-79. https://doi. org/10.1016/j.ecolecon.2012.06.002

Poteete, A. R., M. A. Janssen, and E. Ostrom. 2010. Working together: collective action, the commons, and multiple methods in practice. Princeton University Press, Princeton, New Jersey, USA.

Ragin, C. C. 1989. The comparative method: moving beyond quantitative and qualitative strategies. University of California Press, Berkeley, California, USA.

Ragin, C. C. 2000. Fuzzy-set social science. University of Chicago Press, Chicago, Illinois, USA.

Ragin, C. C. 2008. Redesigning social inquiry: fuzzy sets and beyond. University of Chicago Press, Chicago, Illinois, USA. https://doi.org/10.7208/chicago/9780226702797.001.0001

Ramachandra Rao, A., and V. V. Srinivas. 2006. Regionalization of watersheds by fuzzy cluster analysis. Journal of Hydrology 318 (1-4):57-79. https://doi.org/10.1016/j.jhydrol.2005.06.004

Reckien, D., K. Eisenack, and M. K. B. Lüdeke. 2011. Land consumption by urban sprawl - a new approach to deduce urban development scenarios from actors' preferences. Environmental Modeling and Assessment 16:465-477. https://doi.org/10.1007/ $\underline{\mathrm{s} 10666-011-9254-6}$

Rihoux, B. 2006. Qualitative comparative analysis (QCA) and related systematic comparative methods: recent advances and remaining challenges for social science research. International Sociology 21(5):679-706. https://doi.org/10.1177/0268580906067836

Ripberger, J. T., K. Gupta, C. L. Silva, and H. C. Jenkins-Smith. 2014. Cultural theory and the measurement of deep core beliefs within the advocacy coalition framework. Policy Studies Journal 42(4):509-527. https://doi.org/10.1111/psj.12074
Roggero, M. 2015. Adapting institutions: exploring climate adaptation through institutional economics and set relations. Ecological Economics 118:114-122. https://doi.org/10.1016/j. ecolecon.2015.07.022

Rudel, T. K. 2008. Meta-analyses of case studies: a method for studying regional and global environmental change. Global Environmental Change 18:18-25. https://doi.org/10.1016/j. gloenvcha.2007.06.001

Ruppert-Winkel, C., R. Arlinghaus, S. Deppisch, K. Eisenack, D. Gottschlich, B. Hirschl, B. Matzdorf, T. Mölders, M. Padmanabhan, T. Plieninger, K. Selbmann, and R. Ziegler. 2015. Characteristics, emerging needs and challenges of transdisciplinary sustainability science: experiences from the German SocialEcological Research Program. Ecology and Society 20(3):13. https://doi.org/10.5751/ES-07739-200313

Sassen, S. 1991. The global city: New York, London, Tokyo. Princeton University Press, Princeton, New Jersey, USA. https:// doi.org/10.1515/9781400847488

Schachhuber, A. 2004. Social movements, environmental governance, and rural territorial development: an international perspective. Centro Latinoamericano para el Desarrollo Rural, Santiago, Chile. [online] URL: https://pdfs.semanticscholar. org/3108/59ec836f211ad5b043d3797f31bf8a8ac19d.pdf

Schmid, E., A. Pechan, M. Mehnert, and K. Eisenack. 2017. Imagine all these futures: on heterogeneous preferences and mental models in the German energy transition. Energy Research and Social Science 27:45-56. https://doi.org/10.1016/j.erss.2017.02.012

Schneider, C. Q., and C. Wagemann. 2012. Set-theoretic methods for the social sciences - a guide to qualitative comparative analysis. Cambridge University Press, Cambridge, UK.

Sietz, D. 2014. Regionalisation of global insights into dryland vulnerability: better reflecting smallholders' vulnerability in Northeast Brazil. Global Environmental Change 25:173-185. https://doi.org/10.1016/j.gloenvcha.2014.01.010

Sietz, D., U. Frey, M. Roggero, Y. Gong, N. Magliocca, R. Tan, P. Janssen, and T. Vaclavik. 2019. Archetype analysis in sustainability research: methodological portfolio and analytical frontiers. Ecology and Society 24(3):in press.

Sietz, D., M. K. B. Lüdeke, and C. Walther. 2011. Categorisation of typical vulnerability patterns in global drylands. Global Environmental Change 21(2):431-440. https://doi.org/10.1016/j. gloenvcha.2010.11.005

Sietz, D., S. E. Mamani Choque, and M. K. B. Lüdeke. 2012. Typical patterns of smallholder vulnerability to weather extremes with regard to food security in the Peruvian Altiplano. Regional Environmental Change 12(3):489-505. https://doi.org/10.1007/ s10113-011-0246-5

Sietz, D., J. C. Ordoñez, M. T. J. Kok, P. Janssen, H. B. M. Hilderink, P. Tittonell, and H. Van Dijk. 2017. Nested archetypes of vulnerability in African drylands: where lies potential for sustainable agricultural intensification? Environmental Research Letters 12:095006. https://doi.org/10.1088/1748-9326/aa768b

Sietz, D., and H. Van Dijk. 2015. Land-based adaptation to global change: what drives soil and water conservation in western Africa? 
Global Environmental Change 33:131-141. https://doi.org/10.1016/ j.gloenvcha.2015.05.001

Sitas, N., Z. V. Harmáčková, J. A. Anticamara, A. Arneth, R. Badola, R. Biggs, R. Blanchard, L. Brotons, M. Cantele, K. Coetzer, R. DasGupta, E. Den Belder, S. Ghosh, A. Guisan, H. Gundimeda, M. Hamann, P. A. Harrison, S. Hashimoto, J. Hauck, B. Klatt, K. Kok, R. M. Krug, A. Niamir, P. J. O'Farrell, S. Okayasu, I. Palomo, L. M. Pereira, P. Riordan, F. SantosMartín, O. Selomane, Y. Shin, and M. Valle Tobar. 2019. Exploring the usefulness of scenario archetypes in science-policy processes: experience across IPBES assessments. Ecology and Society 24(3):in press.

Smith, B., and A. C. Varzi. 2000. Fiat and bona fide boundaries. Philosophy and Phenomenological Research 60(2):401-420. https://doi.org/10.2307/2653492

Srinivasan, V., E. F. Lambin, S. M. Gorelick, B. H. Thompson, and S. Rozelle. 2012. The nature and causes of the global water crisis: syndromes from a meta-analysis of coupled human-water studies. Water Resources Research 48(10). https://doi. org/10.1029/2011WR011087

Stoll-Kleemann, S., and C. Pohl. 2007. Evaluation inter- und transdisziplinärer Forschung. Humanökologie und

Nachhaltigkeitsforschung auf dem Prüfstand. Oekom Verlag, Munich, Germany.

Thompson, M., R. J. Ellis, and A. B. Wildavsky. 1990. Cultural theory. Westview, Boulder, Colorado, USA. https://doi. org/10.4324/9780429501180

United Nations Environment Programme (UNEP). 2007. Global environmental outlook 4. United Nations Environment Programme, Nairobi, Kenya. [online] URL: https://www. unenvironment.org/resources/global-environment-outlook-4

Václavík, T., F. Langerwisch, M. Cotter, J. Fick, I. Häuser, S. Hotes, J. Kamp, J. Settele, J. H. Spangenberg, and R. Seppelt. 2016. Investigating potential transferability of place-based research in land system science. Environmental Research Letters 11(9). https://doi.org/10.1088/1748-9326/11/9/095002

Václavík, T., S. Lautenbach, T. Kuemmerle, and R. Seppelt. 2013. Mapping global land system archetypes. Global Environmental Change 23(6):1637-1647. https://doi.org/10.1016/j.gloenvcha.2013.09.004

Vidal Merino, M., D. Sietz, F. Jost, and U. Berger. 2018. Archetypes of climate vulnerability: a mixed-method approach applied in the Peruvian Andes. Climate and Development. https:// doi.org/10.1080/17565529.2018.1442804

Villamayor-Tomás, S., and G. García-López. 2017. The influence of community-based resource management institutions on adaptation capacity: a large-n study of farmer responses to climate and global market disturbances. Global Environmental Change 47:153-166. https://doi.org/10.1016/j.gloenvcha.2017.10.002

Wang, R., K. Eisenack, and R. Tan. 2019. Sustainable rural renewal in China: archetypical patterns. Ecology and Society 24 (3):in press.

Warren, A. 2002. Land degradation is contextual. Land Degradation and Development 13:449-459. https://doi.org/10.1002/ $\underline{1 d r .532}$
Wolstenholme, E. F. 2003. Towards the definition and use of a core set of archetypal structures in system dynamics. Systems Dynamics Review 19(1):7-26. https://doi.org/10.1002/sdr.259

Yin, R. K. 2009. Case study research: design and methods (applied social researchmethods). Sage, Thousand Oaks, California, USA.

Young, O. R., E. F. Lambin, F. Alcock, H. Haberl, S. I. Karlsson, W. J. McConnell, T. Myint, C. Pahl-Wostl, C. Polsky, P. S. Ramakrishnanm, H. Schroeder, M. Scouvart, and P. H. Verburg. 2006. A portfolio approach to analyzing complex humanenvironment interactions: institutions and land change. Ecology and Society 11(2):31. https://doi.org/10.5751/ES-01799-110231 